\title{
Improving Access to, Use of, and Outcomes from Public Health Programs: The Importance of Building and Maintaining Trust with Patients/Clients
}

\author{
Paul Russell Ward* \\ Discipline of Public Health, Flinders University, Adelaide, SA, Australia
}

The central argument in this paper is that "public trust" is critical for developing and maintaining the health and wellbeing of individuals, communities, and societies. I argue that public health practitioners and policy makers need to take "public trust" seriously if they intend to improve both the public's health and the engagement between members of the public and public health systems. Public health practitioners implement a range of services and interventions aimed at improving health but implicit a requirement for individuals to trust the practitioners and the services/interventions, before they engage

OPEN ACCESS

Edited by:

David Preen,

University of Western Australia, Australia

Reviewed by:

Georgi Iskrov,

Plovdiv Medical University, Bulgaria Anuradha Rose,

Christian Medical College, India

*Correspondence:

Paul Russell Ward paul.ward@flinders.edu.au

Specialty section: This article was submitted to

Public Health Policy, a section of the journal Frontiers in Public Health

Received: 21 October 2016 Accepted: 02 February 2017

Published: 08 March 2017

Citation:

Ward PR (2017) Improving Access

to, Use of, and Outcomes from

Public Health Programs:

The Importance of Building and Maintaining Trust with Patients/Clients.

Front. Public Health 5:22. doi: 10.3389/fpubh.2017.00022 with them. I then go on to provide an overview of the theory of trust within sociology and show why it is important to understand this theory in order to promote trust in public health services. I then draw on literature in three classic areas of public healthhospitals, cancer screening, and childhood immunization - to show why trust is vital in terms of understanding and potentially improving uptake of services. The case studies in this paper reveal that public health practitioners need to understand the centrality of building and maintaining trusting relationships with patients/clients because people who distrust public health services are less likely to use them, less likely to follow advice or recommendations, and more likely to have poorer health outcomes.

Keywords: trust, trustworthiness, public health practice, public health policy, sociological theory, cancer screening, childhood immunizations

\section{CENTRALITY OF TRUST IN CONTEMPORARY SOCIETY}

Both theoretical and empirical literatures point to the idea that contemporary society is bound up with decreasing levels of trust $(1,2)$. This declining trust has been witnessed in healthcare (3-9) alongwith other institutions $(1,2,10)$. Some authors argue that public distrust has become the default position in recent times, often evidenced by increasing numbers and strength of belief in conspiracy theories and is the "cultural logic of modernity" (11). Declining public trust has been linked to increased questioning about and confidence in science and experts to "have the right answers," and the proliferation of information in the internet and social media, "When the life-world is colonized by medical insecurity, medicalized subjects come to suspect the messenger and the knowledge they bear" (12) (p. 524). When this public questioning and distrust is applied to public health, one may argue that public health and medical practitioners are no longer able to be regarded as the "experts" around health and illness, since "all knowledge is tentative, corrigible and therefore open to subsequent revision or abandonment...Systems of expertise come to represent multiple sources of authority that are frequently contested and divergent in their implications" (13) (p. 262). With the changing power 
base of medicine in society and the multiple sources of seemingly credible information about how people can/should manage their health and illness, understandably people begin to question who and what to trust. In addition, the increasing confidence and "rights" understood by patients and the public that they can, and should, challenge normative assumptions, such as all healthcare is equal, in their best interests, and trustworthy.

In increasingly complex and ever-changing times, sociologists argue that the public look toward so-called expert systems (e.g., public health, science, and politics) to make predictions about the future, thereby allowing the public to make decisions on the basis of trustworthy information provided by these expert system (14). However, Luhmann identifies the difficulties for expert systems to predict the future, "To show trust is to anticipate the future. It is to behave as though the future were certain" (15) (p. 10). However, the public health system cannot adequately predict future health needs, compelling/driving people to look for other sources of information and to question their trust in public health services (16) and also the systems which are perceived to support them. Indeed, Luhmann stated that "one should expect trust to be increasingly in demand as a means of enduring the complexities of the future which technology will generate" (15) (p. 16). The fact that we can log onto an internet search engine and obtain multiple, contested, and changing answers to our searches (e.g., what are the risks and benefits of childhood immunizations?) has led to a state of existential anxiety ["no man's land" (17); in the "gray zone" (18); "betwixt and between health" (12)], which means that the public may question the validity of public health knowledge (vis a vis other information provided on the internet) and hence, the "trustfulness" of both public health practitioners and their system of knowledge. Indeed, Crawford stylishly suggests that "People are left wondering about the efficacy of medical advice: as the map of danger is filled in, safe passage appears all the more difficult; but as the map of safe passage becomes illegible, people do not know what to believe or how to act in order to be safe" (12) (p. 511). In other words, we cannot simply assume or expect that the public will trust the public health system, "it has continually to be 'won"' (14) and "and is therefore being constantly renegotiated with lay audiences" (19). I use three case studies later in the paper to highlight these issues of trust in different aspects of the public health system.

\section{CONCEPTUALIZATIONS OF TRUST}

Trust has been comprehensively researched and theorized elsewhere (4, 20-27), although I will broadly cover the key points within the theoretical literature in order to highlight both "what trust is" and "why it is important" for public health practitioners and policy makers to think about it carefully when planning public health services, programs, and interventions.

Sociologists identify two types of trust: institutional and interpersonal. Interpersonal trust is regarded as an outcome of interpersonal interactions that people can learn in order to make decisions about future interactions (an individual uses past experiences of similar interactions to predict whether or not to trust someone in the future) $(15,26,28,29)$. I use the initial definition by Sabel (1993:1133) for interpersonal trust, "the mutual confidence that no party will exploit another's vulnerability" (30), within this paper. However, this definition does not include the important addition of "power" within interpersonal relationships, so I extend the previous definition recognizing that to trust others, is to "accept the risks associated with the type and depth of the interdependence inherent in a given relationship" (31). For example, to place trust in a doctor or surgeon has potentially greater risks than placing trust in a shopkeeper or waiter. Institutional trust relates to people investing trust in a system or institution (as distinct from a person), such as a hospital, a medical clinic, or a cancer screening program. Hudson (32) argues that institutional trust is different from interpersonal trust. Mishler and Rose define institutional trust as "the expected utility of institutions performing satisfactorily" (33) (p. 31). Giddens argues that there are social/cultural norms underpinning the decision to trust (outside of actual experience), often based on a stylized idea of the institution (34). Indeed, Fukuyama (35) argues that "trust arises when a community shares a set of moral values in such a way as to create expectations of regular and honest behavior" (p. 153). My own research on trust in different public health services found that it is possible to have trust in one level but not necessarily the other. For example, in a study of trust in hospitals, patients in public hospitals trusted the individual doctors but not necessarily the government funding the hospitals (36). In a study of trust in colorectal cancer (CRC) screening, some cultural groups trusted and some distrusted the government funding the screening, and some groups trusted and others distrusted the health-care professionals involved in the screening $(9,10)$.

Sociologists argue that trust only exists when there is a deficit in knowledge by the person needing to trust (e.g., the patient, client), since there would be no need for trust in a situation where they had complete knowledge (37) - a decision in full knowledge would not require trust. In order for an individual to have "trust" in either a public health practitioner or institution, their decision is a combination of "good reason" (i.e., past experience of trusting relationships and good outcomes) a "leap of faith" that hopefully plugs the gap in their "partial understanding" (37). In this way, trust is a pledge, under conditions of uncertainty, to more than simply cognitive understanding (37). The smaller the "good reason" and the larger the "leap of faith," the higher the risk of trusting. This is often the case in public health, when we cannot always predict whether a treatment will be effective, whether a screening test will be completely accurate, or whether public health practitioners will always act in the best interest of patients or the public.

When mistrust occurs, it often starts from interactions with the people who represent the systems or institutions (e.g., immunization nurses who represent immunization programs, or doctors who represent cancer screening programs). Giddens uses the term "access point" to identify the social situations in which the individual (e.g., public health practitioner) is perceived as representing a particular institution or social system, arguing that "Although everyone is aware that the real repository of trust is in the abstract system, rather than the individuals who in specific contexts 'represent' it, access points carry a reminder that it is the flesh-andblood people (who are potentially fallible) who are its operators" (28) (p. 85). Using this logic, it would follow that institutional 
trust is built on, and predetermined by, interpersonal trust (38). This is critical for public health, since the public health practitioners therefore have a central role in developing, maintaining, and potentially rebuilding trust in public health systems and services.

\section{THE INTERPLAY BETWEEN TRUST AND PUBLIC HEALTH}

This section addresses the importance of trust in key areas of the social determinants of health: socioeconomic security, social inclusion, and social empowerment $(39,40)$.

The definition of socioeconomic security is based on the degree to which people have access to a range of services and systems, including good healthcare and education, safe housing, and appropriate employment opportunities. This domain has great historical credence in public health, and there is a plethora of public health policy (41-45) and research (46-50) in this area. Much of the sociological literature on trust in public health has focused on how trust impacts on patient access to and use of healthcare and highlights the significance of both interpersonal and institutional trust for developing socioeconomic security. In addition, there is a large amount of public health research highlighting the relationship between negative health outcomes and perceptions of economic and psychological insecurity and relative deprivation $(51,52)$. Therefore, there seems to be a relationship between trust and perceptions of socioeconomic security, fitting in with much of the research on social gradients in health $(46,47,51,52)$.

Social inclusion is defined by the extent to which people have appropriate access to services and systems that they require for normal daily living (e.g., health, education, and welfare), and also feel integrated or included within the social relations of "everyday life" $(39,40)$. Social inclusion focuses on whether people "feel part of" or "included in" society, which is inextricably linked to both interpersonal and institutional trust (or distrust) (2, 22, 53-55).

In terms of the relationship between trust and social inclusion, my view is that people and groups cannot feel and be completely "included" unless there are trusting relations, which need to be reciprocated by both parties in the relationship and also trusted portals of access. These trusting relations may be in terms of more micro-level processes-an individual who has recently moved to a new country getting access to and feeling included in local networks. These may also be on a more macro level-policy makers and/or practitioners may exclude (consciously or subconsciously) particular marginalized groups because they are perceived to be untrustworthy. My own research on both interpersonal and institutional trust across six different Asia-Pacific countries highlights the relationship between social inclusion and trust $(1,2,39)$. In these studies, population groups with higher levels of perceived social inclusion also had higher levels of both interpersonal and institutional trust.

Social empowerment is defined by the extent to which an individual's personal capabilities are enabled or disabled within society (40). Social empowerment builds on both social inclusion and socioeconomic security by exploring the enabling (or disabling) factors (e.g., human rights) which empower people to act as autonomous humans. Some research has shown that in situations where individuals exhibit generalized levels of distrust, they also feel completely disempowered-they feel cut off from and let down by various sources of power and therefore that they do not have a "voice" to enable situations to change for the better (56). Of course, the relationship between distrust and disempowerment can work both ways, with both negative feelings feeding off each other.

\section{KEY CASE STUDIES IN OF TRUST IN PUBLIC HEALTH}

I outline literature and some of my own research on trust in different areas of the public health system: hospitals, cancer screening, and childhood immunizations. These have been chosen because they serve different functions, involve different types of healthcare practitioners, and have different treatment/prevention modalities, yet they all suffer from questioning of trust by groups of patients/clients.

\section{TRUST IN HOSPITALS}

A number of public health services and programs are provided in hospitals and dealing with the issue of trust or distrust in hospitals is increasingly important, given the declining trust in Western health-care systems $(4,57)$. There is a need for more research on trust in hospitals and health-care systems more broadly (58), with the authors of one paper stating that we need to "understand, protect and restore public trust in the health care system" (58) (p. 1). If members of the public distrust hospitals and/or the health-care professionals working in them, it creates a difficult situation for them because distrust related to poorer patient outcomes. Low levels of trust are associated with increased risk of psychological distress (59), and patients with low levels of trust are more likely to be in low socioeconomic groups, less likely to seek or access healthcare, less likely to accept healthcare recommendations or maintain continuity of care, and more likely to avoid healthcare, including hospitals, entirely (60). Conversely, higher trust in healthcare enhances the likelihood of return for follow-up care, increases patient adherence to therapies, facilitates health information exchange, and enables providers to encourage necessary behavioral changes (61-65).

An Australian qualitative study found that patient's trust in private hospitals was one of the key reasons why they chose to buy private health insurance (66), and an Australian survey found that private hospitals are invested with higher trust than public hospitals (67). In contrast, research in the US found that publically funded healthcare is invested with higher trust than privately funded healthcare (61). The higher trust in publically funded healthcare in the US may be due to public health-care systems having more transparency, public accountability, and a lack of profit-related motives, thereby increasing public trust in relation to privately funded healthcare that is regarded as being driven by profit-related motives (68).

My own research on trust in public and private hospitals in Australia found that public and private patients made very different assessments about trust in hospitals. Patients in private hospitals made trust-decisions in a very similar manner to 
consumers making purchases-they assessed the various options about possible doctors and/or hospitals, thought about which one was the most trustworthy and then made their choice. In this way, trust and choice went hand in hand. In making their trust-based choice, they relied on both objective and subjective assessments of the reputation of the doctor and/or the hospital, linking better reputation to higher quality healthcare. Patients with private health insurance could "shop around" for particular hospitals and particular doctors in whom they either had positive previous experience or friends/family had similar positive experience. As noted earlier in the section on the sociology of trust, this prior experience reduces the risk in placing trust (reduces the "leap of faith") because the decision to trust is based on a more "reasoned decision". Conversely, patients in public hospitals had no choice in their hospital and/or doctor, since they had been referred (often from their general practitioner) and saw whichever doctor was on duty at that time. The patients in public hospitals often did not know their doctor (larger "leap of faith") and in order to place their trust, patients stated that doctors in public hospitals would try to "do their best", thereby being trustworthy. This level of trust goes back to the definition of trust which is about trusting someone because you think they will do their best for you and assuming that they will not try to do harm. Our data show that both public and private patients can have "trust" in their hospital doctors, but they are based on different rationales and types of evidence. The private patients exhibited a kind of "active trust," and the public patients exhibited a kind of "resigned trust".

\section{TRUST IN CANCER SCREENING}

There is a great deal of research on trust in various forms of cancer screening, but I will focus specifically on CRC screening here. There are a number of known barriers to people undertaking CRC screening, including a lack of knowledge about both their personal CRC risk factors and knowledge about screening (69-71), lack of trust $(72,73)$, fear of the screening test (74), and broader concerns about the effectiveness and purpose of cancer screening (73).

Making a decision about whether or not to participate in a population-based screening program such as CRC screening is likely to involve a trust-based decision because the majority of potential participants will be asymptomatic and are likely to have low knowledge about the program or indeed CRC, therefore requiring trust via a "leap of faith" (20). In other words, most members of the public do not have in-depth knowledge of screening programs, and therefore rely on "trusting" particular public health practitioners or public health institutions-this "trust" allows them to make decisions and allow for their imperfect knowledge (75).

Most of the research on trust in cancer screening programs has understandably focused on screening methods that includes the intervention of medical professionals $(72,76,77)$, since the researchers can examine the impact of interpersonal trust in improving screening rates. Indeed, people with higher trust in their doctor are more likely to undertake screening tests $(72,77$, 78). US research with women found higher trust in screening programs undertaken within health centers (e.g., Pap smear, clinical breast exam) but lower trust in screening programs requiring women to perform the tests themselves and at home (e.g., breast self-examination and CRC screening) (77). The higher trust in screening undertaken in health centers as opposed to more "faceless" screening at home maybe due to the involvement of interpersonal (e.g., doctor) trust-this fits in with the idea of the "access point" between interpersonal and institutional trust mentioned earlier in the paper. However, a number of population-based CRC screening programs, including Australia, do not involve any health-care professionals in the initial screening test, which involves people performing an immunochemical fecal occult blood test in their own home and then mailing it to a central laboratory.

My own, along with colleagues, research on trust in CRC screening in Australia identified different types of trust and distrust by different population groups $(9,10)$. We highlighted the nuances and complexities involved in the trustworthiness of the CRC screening program, which included trust considerations at different levels: interpersonal relationships with people perceived as linked to the CRC screening program (e.g., GP, Aboriginal Health Worker), local area issues that impacted on the program (e.g., trustworthiness of postal system or local health center) and national political issues (e.g., trustworthiness of the government and particular politicians seen the "represent" the government). At a more abstract level, there was questioning about the ability of doctors to actually diagnose or treat cancer (questioning the "point" of screening) and the scientific procedures in laboratories to identify blood in the small amount of feces required for the screening test (questioning the validity of the screening). Levels of trust differed between cultural groups, with the Indigenous participants having mistrust in government and services run by the government, including health services, the postal service (required to obtain and send the screening test) and the CRC screening program. This mistrust in government led Indigenous participants to be much less likely to take part in the CRC screening program. In contract, Anglo-Australian and Iranian groups had much higher trust in the government, leading them to be more likely to undertake the CRC screening. In order to improve CRC screening (and probably engagement with many more public health services), the issues of broad mistrust in government need to be addressed in order to increase trustworthiness of, and trust/participation in public health services, particularly for Indigenous Australian people.

\section{TRUST IN CHILDHOOD IMMUNIZATIONS}

Childhood immunization programs have been so effective in the elimination of infectious disease that they have become a victim of their own success (79), with some people now questioning the need for childhood immunizations due to their perception that certain diseases are rare and therefore less concerning (80). Public health practitioners thus have to engage with, and promote the benefits of, vaccination to groups who are increasingly unlikely to have encountered some of the diseases they are being asked to vaccinate their children against.

The increasing debate in Western society regarding the real or perceived adverse events following vaccination has made some 
parents "uneasy" about the decision to vaccinate their children (81). This "unease" or "uncertainty" is called "vaccine hesitancy" (82), and approximately $20-30 \%$ of all parents in some countries are vaccine hesitant $(80,83)$. The literature attempting to understand this phenomenon reveals mistrust as a key factor, but there lacks a rich theoretical exploration of the interaction between trust and vaccine hesitancy and specifically how trust in vaccines is eroded and maintained.

There are a number of concerns that parents hold regarding vaccines, mostly centered on concerns about vaccine safety (84). The immunization process induces complex, emotional decisions in some parents who are faced with potentially difficult choices, such as attempting to balance the individual rights of their child with the broader health protection of the community (85). Other widely held concerns by vaccine hesitant parents are as follows: the perceived high number of vaccinations given to children; that health professionals may provide inadequate information; that health professionals are perceived to be unwilling to spend adequate time providing vaccine information; and that vaccines may be perceived to overload their child's immune system, vaccine components may be harmful, and alternative medicines may suffice in place of vaccines (84). The final concern regarding vaccine hesitancy concerns trust. Not only do some parents distrust the medical system but anything recommended by government institutions (83). A core research question that resulted from the 2014 report by American Academy of Arts and Sciences, entitled "Public Trust in Vaccines: Defining a Research Agenda" was, "To what extent does vaccine hesitancy result from broader distrust in government and science" [(83) p. 10]. This question resonates with other recent literature which cites "trust" as critically important in the decision for parents to vaccinate (86-89). Trust in vaccines and vaccination is complex: it describes a continuum of trust from the funding of immunology research, to vaccine design and manufacture, through government decision making regarding which vaccinations to fund for immunization programs, to the point at which a vaccine is administered by the medical provider to the individual. The parental decision to vaccinate or not is both the beginning and the end point of the vaccine journey and if distrust is evident at any point in this journey then there is a potential for vaccine rejection.

Public trust in vaccinations, and the health professionals who promote them, has been identified in the literature as pivotal in determining whether parents will decide to immunize their child $(80,90)$. Parental perceptions of insufficient, biased, poorly communicated advice from health-care providers is noted in the literature as key to a lack of trust in vaccinations (90) with the result that individuals may turn to the internet for advice, where they may compound their confusion with a multitude of conflicting and unregulated material so that it is difficult to discriminate between the evidence-based sources and those based on anecdote and misinformation $(87,91)$.

Maintenance of institutional trust is paramount to immunization programs. For example, concerns regarding trust in institutions involved in vaccinations during the 2009 influenza $\mathrm{H} 1 \mathrm{~N} 1$ pandemic led to increasing hesitancy to vaccinate, linked to conspiracy theories, and speculation that the pandemic response was influenced by commercial interests (79). This distrust was further promulgated in Australia when the 2010 seasonal influenza vaccine for children was withdrawn due to an observed increase in febrile convulsions, later found to be linked to one vaccine brand. Despite the resumption of the vaccine program with other vaccine brands, persistent mistrust, and confusion is linked to a decline in influenza vaccination coverage. It is also argued that institutional trust is being eroded by current social trends toward patient advocacy, empowerment, and patient choice, being at odds with the traditional approach to public health programs, which is increased further with virtually unlimited access to health information via sources, such as social media and the internet (79). Given the importance of understanding parental (dis)trust in childhood immunizations, I am currently part of a research team undertaking in-depth qualitative research to further develop our understanding. Our first paper from this study outlines the ways in which broad distrust in multinational pharmaceutical companies impacts some parents trust in childhood vaccinations and their decisions not to vaccinate their children (92). A number of parents perceived that pharmaceutical companies were motivated purely by profits and had the global power and reach to influence governments and research institutions and thus questioned whether they were indeed "working for the best interests of children", a key issue in trustworthiness. The immunizations were therefore imbued with distrust, not necessarily due to the ingredients of the vial, but the various institutions that have created and marketed it. Rebuilding trust in this example may require "distancing" the immunization from the pharmaceutical companies and being clearer on the independence of researchers (and the scientific system) and governments (and the political system) in making decisions on childhood immunization policy and practice.

\section{CONCLUSION}

Contemporary public health systems are located historically and culturally within a society whereby individuals question, research, interrogate, and seek alternatives to "traditional" approaches to health and illness. The push to modernity has meant that public health practitioners can no longer just assume that patients or the public will simply "trust" them because of their position in society or their extensive training. Therefore, trust needs to be won and kept because "trust comes on foot and goes away of horseback" (93) (p. 389). In other words, once trust has been lost, it is very difficult to regain it. This is critically important because, as I have shown using numerous examples from different areas of public health, people who distrust public health services are less likely to use them, less likely to follow advice or recommendations, and more likely to have poorer health outcomes. Therefore, public health practitioners need to understand the centrality of trust in their roles. They need to understand the importance of engaging meaningfully and in a trustworthy fashion to build and maintain trust in those groups who are currently mistrusting and to maintain trust in all other groups.

\section{AUTHOR CONTRIBUTIONS}

PW developed the ideas, reviewed the literature, and wrote the paper. 


\section{REFERENCES}

1. Ward P, Mamerow L, Meyer S. Interpersonal trust across six Asia-Pacific countries: testing and extending the 'high trust society' and 'low trust society' theory. PLoS One (2014) 9(4):e95555. doi:10.1371/journal.pone.0095555

2. Ward P, Miller E, Pearce A, Meyer S. Predictors and extent of institutional trust in government, banks, the media and religious organisations: evidence from cross-sectional surveys in six Asia-Pacific countries. PLoS One (2016) 11(10):e0164096. doi:10.1371/journal.pone.0164096

3. Russell S. Treatment-seeking behaviour in urban Sri Lanka: trusting the state, trusting private providers. Soc Sci Med (2005) 61(7):1396-407. doi:10.1016/j. socscimed.2004.11.077

4. Gilson L. Trust and the development of health care as a social institution. Soc Sci Med (2003) 56(7):1453-68. doi:10.1016/S0277-9536(02)00142-9

5. Welsh T, Pringle M. Social capital. Trusts need to recreate trust. Br Med J (2001) 323(7306):177-8. doi:10.1136/bmj.323.7306.177

6. Mechanic D, Meyer S. Concepts of trust among patients with serious illness. Soc Sci Med (2000) 51(5):657-68. doi:10.1016/S0277-9536(00)00014-9

7. Davies H. Falling public trust in health services: implications for accountability. J Health Serv Res Policy (1999) 4(4):193-4. doi:10.1177/135581969900400401

8. Birungi H. Injections and self-help: risk and trust in Ugandan health care. Soc Sci Med (1998) 47(10):1455-62. doi:10.1016/S0277-9536(98)00194-4

9. Ward PR, Coffey C, Meyer S. Trust, choice and obligation: a qualitative study of enablers of colorectal cancer screening in South Australia. Sociol Health Illn (2015) 37(7):988-1006. doi:10.1111/1467-9566.12280

10. Ward P, Coffey C, Javanparast S, Wilson C, Meyer S. Institutional (mis) trust in colorectal cancer screening: a qualitative study with Greek, Iranian, Anglo-Australian and Indigenous groups. Health Expect (2015) 18:2915-27. doi:10.1111/hex.12276

11. Aupers S. 'Trust no one': modernization, paranoia and conspiracy culture. Eur J Commun (2012) 27(1):22-34. doi:10.1177/0267323111433566

12. Crawford R. Risk ritual and the management of control and anxiety in medical culture. Health (London) (2004) 8(4):505-28. doi:10.1177/1363459304045701

13. Williams SJ, Calnan M. Modern Medicine. Lay Perspectives and Experiences. London: UCL Press (1996).

14. Beck GA, Lash S. Reflexive Modernization: Politics, Tradition and Aesthetics in the Modern Social Order. Oxford: Blackwell Publishers (1994).

15. Luhmann N. Trust and Power. New York: Wiley (1979).

16. Wynne B. May the sheep safely graze? A reflexive view of the expert-lay knowledge divide. In: Lash S, Szerszynski B, Wynne B, editors. Risk, Environment and Modernity: Towards a New Ecology. London: SAGE (1996). p. 44-83.

17. Armstrong D. Public health spaces and the fabrication of identity. Sociology (1993) 27:393-410. doi:10.1177/0038038593027003004

18. Gifford S. The meaning of lumps: a case study of the ambiguities of risk. In: Nettleton S, Gustafsson U, editors. The Sociology of Health and Illness Reader. Cambridge: Polity (2002). p. 211-22.

19. Bissell P, Ward PR, Noyce PR. The dependent consumer: reflections on accounts of the risks of non-prescription medicines. Health (London) (2001) 5:5-30. doi:10.1177/136345930100500101

20. Mollering G. The nature of trust: from Georg Simmel to a theory of expectation, interpretation and suspension. Sociology (2001) 35:403-20. doi:10.1017/ S0038038501000190

21. Misztal B. Trust in Modern Societies. Cambridge: Polity Press (1996).

22. Misztal B. Trust and cooperation: the democratic public sphere. J Sociol (2001) 37(4):371-86. doi:10.1177/144078301128756409

23. Gilson L. Trust in health care: theoretical perspectives and research needs. J Health Organ Manag (2006) 20(5):359-75. doi:10.1108/14777260610701768

24. Gilson L, Palmer N, Schneider H. Trust and health worker performance: exploring a conceptual framework using South African evidence. Soc Sci Med (2005) 61(7):1418-29. doi:10.1016/j.socscimed.2004.11.062

25. Gambetta D. Trust: Making and Breaking Co-Operative Relations. Oxford: Basil Blackwell (1988)

26. Luhmann N. Familiarity, confidence, trust: problems and alternatives. In: Gambetta D, editor. Trust: Making and Breaking Cooperative Relations. Oxford: Blackwell (2000). p. 94-108.

27. Luhmann N. Trust: making and breaking cooperative relations. In: Gambetta D, editor. Familiarity, Confidence, Trust: Problems and Alternatives. New York: Basil Blackwell (1988). p. 94-107.
28. Giddens A. The Consequences of Modernity. Cambridge: Polity Press (1990). 29. Mollering G. Trust: Reason, Routine, Reflexivity. Oxford: Elsevier (2006).

30. Sabel CF. Studied trust - building new forms of cooperation in a volatile economy. Human Relat (1993) 46(9):1133-70. doi:10.1177/001872679304600907

31. Shepard BH, Sherman DM. The grammars of trust and general implications. Acad Manage Rev (1998) 23:422-38. doi:10.5465/AMR.1998.926619

32. Hudson J. Institutional trust and subjective wellbeing across the EU. Kyklos (2006) 59(1):43-62. doi:10.1111/j.1467-6435.2006.00319.x

33. Mishler W, Rose R. What are the origins of political trust? Testing institutional and cultural theories in post-Communist societies. Comp Polit Stud (2001) 34:30-62. doi:10.1177/0010414001034001002

34. Govier T. Dilemmas of Trust. Montreal: McGill-Queen's University Press (1998).

35. Fukuyama F. Trust: The Social Virtues and Creation of Prosperity. London: Free Press (1996).

36. Ward P, Rokkas P, Cenko C, Pulvirenti M, Dean N, Carney S, et al. A qualitative study of patient (dis)trust in public and private hospitals: the importance of choice and pragmatic acceptance for trust considerations in South Australia. BMC Health Serv Res (2015) 15:297. doi:10.1186/s12913-015-0967-0

37. Giddens A. Modernity and Self-Identity: Self and Society in the Late Modern Age. Stanford: Stanford University Press (1991).

38. Meyer S, Ward P, Coveney J, Rogers W. Trust in the health system: an analysis and extension of the social theories of Giddens and Luhmann. Health Soc Rev (2008) 17(2):177-86. doi:10.5172/hesr.451.17.2.177

39. Ward P, Mamerow L, Meyer S. Identifying vulnerable populations using a Social Determinants of Health framework: analysis of national survey data across six Asia-Pacific countries. PLoS One (2013) 8(12):e83000. doi:10.1371/ journal.pone.0083000

40. Ward P, Meyer S, Verity F, Gill T, Luong T. Complex problems require complex solutions: the utility of social quality theory for addressing the Social Determinants of Health. BMC Public Health (2011) 11(1):630. doi:10.1186/1471-2458-11-630

41. Ostlin P, Braveman P, Dachs N; WHO Task Force on Research Priorities for Equity in Health, WHO Equity Team. Priorities for research to take forward the health equity policy agenda. Bull World Health Organ (2005) 83:948-53.

42. Department of Health. Independent Inquiry into Inequalities in Health Report. London: Stationary Office (1998).

43. Department of Health. Tackling Health Inequalities: Status Report on the Programme for Action. London: Department of Health (2005).

44. Department of Health. Tackling Health Inequalities: 10 Years On. A Review of Developments in Tackling Health Inequalities in England Over the Last 10 years. London: Department of Health (2009).

45. Department of Health and Ageing. Australian Better Health Initiative. Canberra: Department of Health and Ageing (2009).

46. Wilkinson RG, Pickett KE. The problems of relative deprivation: why some societies do better than others. Soc Sci Med (2007) 65(9):1965-78. doi:10.1016/j.socscimed.2007.05.041

47. Wilkinson RG, Pickett KE. Income inequality and population health: a review and explanation of the evidence. Soc Sci Med (2006) 62(7):1768-84. doi:10.1016/j.socscimed.2005.08.036

48. Commission on Social Determinants of Health. Action on the Social Determinants of Health: Learning from Previous Experiences. Geneva: World Health Organisation (2005).

49. Commission on Social Determinants of Health. Achieving Health Equity: from Root Causes to Fair Outcomes. Geneva: World Health Organisation (2007).

50. Commission on Social Determinants of Health. Closing the Gap in a Generation: Health Equity through Action on the Social Determinants of Health. Final Report of the CSDH. Geneva: World Health Organisation (2008).

51. Marmot M, Wilkinson R. Social Determinants of Health. Oxford: Oxford University Press (2006).

52. Wilkinson R, Pickett K. The Spirit Level. What Greater Equality Makes Stronger Societies. New York: Bloomsbury Press (2009).

53. Bornstein B, Tomkins A. Institutional trust: an introduction. In: Bornstein B, Tomkins A, editors. Motivating Compliance and Cooperation with Authority ihe Role of Institutional Trust. Switzerland: Springer International Publishing (2015). p. 1-11.

54. Cole L, Cohn E. Institutional trust across cultures: its definitions, conceptualizations, and antecedents across Eastern and Western European nations. 
In: Shockley E, Neal T, PytlikZillig L, Bornstein B, editors. Interdisciplinary Perspectives on Trust. Basel: Springer International Publishing (2016). p. 157-76.

55. Sønderskov K, Dinesen P. Trusting the State, trusting each other? The effect of institutional trust on social trust. Polit Behav (2016) 38:179-202. doi:10.1007/ s11109-015-9322-8

56. Ward P, Coates A. "We shed tears but there is no one there to wipe them up for us": narratives of (mis)trust in a materially deprived community. Health (London) (2006) 10:283-302. doi:10.1177/1363459306064481

57. BrownPR.TrustinginthenewNHS: instrumentalversuscommunicativeaction. Sociol Health Illn (2008) 30(3):349-63. doi:10.1111/j.1467-9566.2007.01065.x

58. Gille F, Smith S, Mays N. Why public trust in health care systems matters and deserves greater research attention. J Health Serv Res Policy (2015) 20(1):62-4. doi:10.1177/1355819614543161

59. Ahnquist J, Wamala SP, Lindstrom M. What has trust in the health-care system got to do with psychological distress? Analyses from the national Swedish survey of public health. Int J Qual Health Care (2010) 22(4):250-8. doi:10.1093/intqhc/mzq024

60. Armstrong K, Rose A, Peters N, Long JA, McMurphy S, Shea JA. Distrust of the health care system and self-reported health in the United States. JGen Intern Med (2006) 21(4):292-7. doi:10.1111/j.1525-1497.2006.00396.x

61. Mechanic D. Changing medical organization and the erosion of trust. Milbank Q (1996) 74(2):171-89. doi:10.2307/3350245

62. Mechanic D. Public trust and initiatives for new health care partnerships. Milbank Q (1998) 76(2):281-302. doi:10.1111/1468-0009.00089

63. Thiede M. Information and access to health care: is there a role for trust. Soc Sci Med (2005) 61(7):1452-62. doi:10.1016/j.socscimed.2004.11.076

64. Thom DH. Training physicians to increase patient trust. J Eval Clin Pract (2000) 6(3):245-53. doi:10.1046/j.1365-2753.2000.00249.x

65. Thom DH, Kravitz RL, Bell RA, Krupat E, Azari R. Patient trust in the physician: relationship to patient requests. Fam Pract (2002) 19(5):476-84. doi:10.1093/fampra/19.5.476

66. Natalier K, Willis K. Taking responsibility or averting risk? A socio-cultural approach to risk and trust in private health insurance decision. Health Risk Soc (2008) 10(4):399-411. doi:10.1080/13698570802167413

67. Hardie EA, Crichley CR. Public perceptions of Australia's doctors, hospitals and health care systems. Med J Aust (2008) 189(4):210-4.

68. Schlesinger M, Quon N, Wynia M, Cummins D, Gray B. Profit-seeking, corporate control, and the trustworthiness of health care organizations: assessments of health plan performance by their affiliated physicians. Health Serv Res (2005) 40(3):605-45. doi:10.1111/j.1475-6773.2005.00377.x

69. Christou A, Katzenellenbogen JM, Thompson S. Australia's National Bowel Cancer Screening Program: does it work for Indigenous Australians? BMC Public Health (2010) 10:373. doi:10.1186/1471-2458-10-373

70. Greiner K, James A, Born W, Hall S, Engelman K, Okuyemi K, et al. Predictors of fecal occult blood test (FOBT) completion among low-income adults. Prev Med (2005) 41:767-684. doi:10.1016/j.ypmed.2004.12.010

71. Salimzadeh H, Delavari A, Montazeri A, Mirzazadeh A. Knowledge and practices of Iranians toward colorectal cancer and barriers to screening. Int J Prev Med (2012) 3(1):29-35.

72. Born W, Engelman K, Greiner KA, Bhattacharya S, Hall S, Hou O, et al. Colorectal cancer screening, perceived discrimination, and low-income and trust in doctors: a survey of minority patients. BMC Public Health (2009) 9:363. doi:10.1186/1471-2458-9-363

73. Javanparast S, Ward P, Carter S, Wilson C. Barriers to and facilitators of colorectal cancer screening in different population sub-groups in Adelaide, South Australia. Med J Aust (2012) 196(8):521-3. doi:10.5694/mja11.10701

74. Jones R, Devers K, Kuzel A, Woolf S. Patient-reported barriers to colorectal screening. A mixed methods analysis. Am J Prev Med (2010) 38(5):508-16. doi:10.1016/j.amepre.2010.01.021

75. Meyer S, Ward P. Differentiating between trust and dependence of patients with coronary heart disease: furthering the sociology of trust. Health Risk Soc (2013) 15(3):279-93. doi:10.1080/13698575.2013.776017

76. Bynum S, Davis J, Green L, Katz R. Unwillingness to participate in colorectal cancer screening: examining fears, attitudes, and medical mistrust in an ethnically diverse sample of adults 50 years and older. Am J Health Promot (2012) 26(5):295-301. doi:10.4278/ajhp.110113-QUAN-20

77. O'Malley A, Sheppard V, Schwartz M, Mandelblatt J. The role of trust in use of preventative services among low-income African-American women. Prev Med (2004) 39:777-85. doi:10.1016/j.ypmed.2004.01.018

78. Hall MA, Dugan E, Zheng B, Mishra AK. Trust in physicians and medical institutions: what is it, can it be measured, and does it matter? Milbank $Q$ (2001) 79(4):613-39. doi:10.1111/1468-0009.00223

79. Yaqub O, Castle-Clarke S, Sevdalis N, Chataway J. Attitudes to vaccination: a critical review. Soc Sci Med (2014) 112(0):1-11. doi:10.1016/j. socscimed.2014.04.018

80. Leask J, Kinnersley P, Jackson C, Cheater F, Bedford H, Rowles G. Communicating with parents about vaccination: a framework for health professionals. BMC Pediatr (2012) 12(1):154. doi:10.1186/1471-2431-12-154

81. Sadaf A, Richards JL, Glanz J, Salmon DA, Omer SB. A systematic review of interventions for reducing parental vaccine refusal and vaccine hesitancy. Vaccine (2013) 31(40):4293-304. doi:10.1016/j.vaccine.2013.07.013

82. Larson HJ, Jarrett C, Eckersberger E, Smith DMD, Paterson P. Understanding vaccine hesitancy around vaccines and vaccination from a global perspective: a systematic review of published literature, 2007-2012. Vaccine (2014) 32(19):2150-9. doi:10.1016/j.vaccine.2014.01.081

83. American Academy of Arts and Sciences. Pubic Trust in Vaccines: Defining a Research Agency. Cambridge, MA: American Academy of Arts and Sciences (2104).

84. Samad L, Butler N, Peckham C, Bedford H. Incomplete immunisation uptake in infancy: maternal reasons. Vaccine (2006) 24(47-48):6823-9. doi:10.1016/j. vaccine.2006.06.039

85. Downs JS, de Bruin WB, Fischhoff B. Parents' vaccination comprehension and decisions. Vaccine (2008) 26(12):1595-607. doi:10.1016/j.vaccine.2008.01.011

86. Brownlie J, Howson A. 'Leaps of faith' and MMR: an empirical study of trust. Sociology (2005) 39:221-39. doi:10.1177/0038038505050536

87. Kata A. Anti-vaccine activists, Web 2.0, and the postmodern paradigm - an overview of tactics and tropes used online by the anti-vaccination movement. Vaccine (2012) 30(25):3778-89. doi:10.1016/j.vaccine.2011.11.112

88. Reich J. Neoliberal mothering and vaccine refusal. Imagined gated communities and the privilege of choice. Gender Soc (2014) 28(5):679-704. doi:10.1177/0891243214532711

89. Ward JK. Rethinking the antivaccine movement concept: a case study of public criticism of the swine flu vaccine's safety in France. Soc Sci Med (2016) 159:48-57. doi:10.1016/j.socscimed.2016.05.003

90. Brown KF, Kroll JS, Hudson MJ, Ramsay M, Green J, Long SJ, et al. Factors underlying parental decisions about combination childhood vaccinations including MMR: a systematic review. Vaccine (2010) 28(26):4235-48. doi:10.1016/j.vaccine.2010.04.052

91. Kata A. A postmodern Pandora's box: anti-vaccination misinformation on the internet. Vaccine (2010) 28(7):1709-16. doi:10.1016/j.vaccine.2009.12.022

92. Attwell K, Leask J, Meyer S, Rokkas P, Ward P. Vaccine rejecting parents' engagement with expert systems that inform vaccination programs Journal of Bioethical Inquiry. J Bioeth Inq (2016). doi:10.1007/s11673-016-9756-7

93. Kampen J, De Walle S, Bouckaert G. Assessing the relation between satisfaction with public service delivery and trust in government. The impact of the predisposition of citizens toward government on evaluations of its performance. Public Perform Manage Rev (2006) 29(4):387-404.

Conflict of Interest Statement: The author declares that the research was conducted in the absence of any commercial or financial relationships that could be construed as a potential conflict of interest.

Copyright $(2017$ Ward. This is an open-access article distributed under the terms of the Creative Commons Attribution License (CC BY). The use, distribution or reproduction in other forums is permitted, provided the original author(s) or licensor are credited and that the original publication in this journal is cited, in accordance with accepted academic practice. No use, distribution or reproduction is permitted which does not comply with these terms. 